ARTICLE HISTORY: Received: January 6, 2021 Accepted: February 24, 2021 Published: March 3, 2021

УДК 336.711

НАПРАВЛЕНИЯ СОВЕРШЕНСТВОВАНИЯ УПРАВЛЕНИЕМ БАНКОВСКИМИ РИСКАМИ

Чайкина Елена Васильевна,

к.э.н., доцент

Махота Алина Николаевна,

магистрант

Институт финансов, экономики и управления

ФГАОУ ВО «Севастопольский государственныій университет»

Севастополь, Россия

\title{
DIRECTIONS FOR IMPROVEMENT OF BANKING RISK MANAGEMENT
}

\author{
Chaikina Elena Vasilievna, \\ Candidate of Economic Sciences, Associate Professor \\ Makhota Alina Nikolaevna, \\ undergraduate \\ Institute of Finance, Economics and Management \\ FSAEI HE "Sevastopol State University" \\ Sevastopol, Russia
}

\begin{abstract}
Аннотация. Банковские риски являются одной из наиболее важных проблем деятельности кредитных организаций, поскольку оказывают непосредственное влияние на финансовое положение коммерческого банка и всей финансовой систем нашей страны. В данной статье рассмотрены сущность банковского риска, его виды и причины возникновения. Обобщены причины возникновения банковских рисков как внешнего, так и внутреннего характера. Систематизированы принципы создания эффективной системы управления рисками. Обобщены стратегические и тактические методы и инструменты управления рисками. Выявлены обязательные элементы повышения эффективности системы правления банковскими рисками.

Abstract. Banking risks are one of the most important problems of credit institutions, as they have a direct impact on the financial situation of a commercial bank and the entire financial system of our country. This article discusses the essence of banking risk, its types and causes. The reasons for the occurrence of bank risks of both external and internal nature are summarized. The principles of creating an effective risk management system are systematized. Strategic and tactical methods and tools of risk management are summarized. The mandatory elements of improving the efficiency of the bank risk management system are identified.

Ключевые слова: банковский риск, внутренние риски, внешние риски, стратегия управления рисками, инструменты управления рисками.

Keywords: bank risk, internal risks, external risks, risk management strategy, risk management tools.

В условиях динамично развивающейся экономической среды функционирования банковской системы, возникновения различного рода макроэкономических финансовых кризисов, банки, как основа финансовой системы страны, оказываются заложниками ситуации. Четко отработанная банковская система порой не может противостоять многочисленным кризисным явлениям, которые зачастую происходят одновременно. Обусловлено это тем, что банковской деятельности присущи широта охвата сферы денежного обращения, которая включает в себя денежный оборот как на макроуровне, так и на микроуровне, а также высокий уровень риска при выполнении любых банковских операций. Одной из причин невозможности противостояния кризисным явлениям в экономике, и отсутствия возможности нивелировать их последствия, является неэффективное управление банковскими рисками [2].

Для того, чтобы сформулировать основные направления совершенствования управления банковскими рисками, необходимо дать определение его сущности. Банковский риск представляет собой вероятность возникновения ожидаемого или неожидаемого события, которое может оказать негативное влияние на капитал и доходы банка.

Надежность и эффективность самого банка зависит от способности своевременно реагировать на изменения во внешней и внутренней среде посредством применения инструментов системы управления банковскими рисками. Такая система представляет собой использование совокупности мер и приемов, направленных на
\end{abstract}


своевременное прогнозирование рисков, определение их величины и степени влияния на финансовое положение банка, что позволяет предотвратить такие риски или минимизировать связанные с ними потери [5].

Возникновение банковских рисков обусловлено сложным переплетением внешних и внутренних факторов, а сама деятельность кредитного учреждения подвержена постоянному риску в силу специфики работы, а именно функционированию на денежном рынке.

Внешние риски не связаны с деятельностью самого банка и возникают в силу обстоятельств экономического и политического характера. Кредитное учреждение не может оказать никакого влияния на процессы, в результате которых возникают внешние риски, и вынуждено принять их как свершившийся факт, в соответствии с которым необходимо предпринимать меры по снижению их негативного влияния.

Внутренние риски представляют собой те специфические факторы функционирования данного конкретного банка, в результате влияния которых банк может потерять финансовые ресурсы от основной и вспомогательной деятельности. Наиболее распространенной группой риска являются операции от основной деятельности. Сюда входят кредитный, процентный, валютный и рыночный риски. К рискам по вспомогательной деятельности включают в себя потери в результате предоставления депозитов, риски при ведении новой деятельности и риски банковских злоупотреблений [1].

Стратегия управления банковскими рисками должна быть направлена на формирование и использование комплекса инструментов для избежания внутренних рисков и нивелирования последствий внешних рисков. Она должна включать в себя комплекс правил и ограничений при осуществлении той или иной банковской операции, реализации того или иного направления банковской деятельности, а также четкий алгоритм принятия решений в нестандартных ситуациях, которые могут вызвать высокий уровень риска.

Тактика управления кредитными рисками должна включать в себя разработку и внедрение в текущую деятельность банка методов и приемов для достижения поставленной цели в конкретно заданных условиях функционирования. Ключевой задачей тактики управления кредитными рисками является выбор оптимального решения и приемлемых в каждой конкретной ситуации методов и приемов управления рисками. Основными методами и приемами управления рисками на тактическом уровне являются: предотвращение риска, удержание риска, передача риска, снижение степени риска путем диверсификации, лимитирования, страхование.

Деятельность любого коммерческого банка должна быть нацелена на постоянное совершенствование системы управления рисками, что предусматривает упорядочение и координирование в пространстве и времени действий всех субъектов управления рисками с целью достижения максимального эффекта функционирования структурных подразделений банка.

Важной частью совершенствования системы управления банковскими рисками в кредитном учреждении является разработка и следование определенным принципам, функциям и методам управления рисками.

Принципы управления рисками должны разрабатываться на основе предыдущего опыта деятельности кредитного учреждения и опыта функционирования других банков и должны быть нацелены на обеспечение стабильности работы банка в процессе реализации принятых решений.

К основным принципам, которыми должны руководствоваться банки при создании эффективной системы управления рисками, относятся:

- целенаправленность, что заключается в определении целей управления рисками в зависимости от направлений деятельности кредитного учреждения;

- последовательность, то есть выработка определенной последовательности действий при сборе и систематизации информации о вероятности возникновения рисковых ситуаций, проведении анализа деятельности, планировании деятельности на основе проведенного анализа, стимулировании активности клиентов с целью увеличения прибыли и минимизации рисков;

- системность, что предусматривает формирование управления рисками как системы, имеющей набор определенных элементов, тесно связанных между собой и способных оказывать влияние друг на друга посредством применения определенных мер;

- согласованность целей, результатов деятельности и способов их достижения, то есть решения в сфере правления рисками должны быть взаимозависимы и не противоречить друг другу;

- единство стратегии управления рисками со стратегией развития банка в целом, то есть методы и инструменты в сфере управления рисками должны быть направлены на достижение стратегических целей банка;

- динамичность, что предусматривает своевременную и четкую реакцию менеджеров на изменение параметров деятельности во внутреннюю и внешнюю среду банка;

- единство теории и практики, то есть методы, формы и инструменты управления рисками должны быть научно обоснованными, а принятые решениями логичными и направленными на решение конкретных практических задач;

- распределение функций, то есть на каждого ответственного работника кредитного учреждения должны быть возложены определенные функции управления рисками, за которые он должен нести персональную ответственность; 
- надежность, то есть создание условий непрерывности управления рисками и гарантий безопасного функционирования банка в настоящем и будущем [3].

Эффективная система управления рисками должна базироваться на планировании деятельности по управлению рисками, то есть должны быть разработаны конкретные мероприятия и задачи относительно реализации стратегии банка и достижения тактических задач в рамках реализации тактических планов в сфере управления рисками.

Важное значение при этом имеет оперативное планирование, то есть планирование, которое ориентировано на решение краткосрочных задач банка. Результатов оперативного планирования является разработка и получение требуемых параметров - количественных и качественных показателей оценки рисков [2].

Одним из ключевых элементов совершенствования управления рисками является организационная структура, в которой закреплены полномочия, задачи и обязанности работников в различных подразделениях и на различных уровнях управления рисками банка. Организационная структура управления рисками должна быть построена таким образом, чтобы обеспечить распределение функциональных обязанностей по предупреждению, контролю и снижению уровня риска между структурными подразделениями банка. В то же время должны быть обеспечены взаимосвязь и взаимоконтроль между различными уровнями управления рисками и возможность распределения и координации задач.

Обеспечение постоянного контроля также является важным направлением деятельности по управлению рисками банка. Мониторинг рисков должен проводиться посредством проверки документации отдельных направлений деятельности управления рисками, сравнения фактических показателей с нормативными, проведении периодических ревизий договорных условий кредитования, выполнения лимитов по кредитованию отдельных видов деятельности. Контроль позволяет выявить отклонения от избранной политики управления рисками, невыполнение ил халатное выполнение работниками своих обязанностей относительно возложенных функций по правлению рисками, вовремя выявить возможные риски отдельных банковских операций [3].

Отдельной функцией эффективного управления рисками банка является анализ рисков, который осуществляется с целью сравнения показателей до и после внедрения мер по предупреждению и нивелированию риска. Особенностью анализа риска является использование их результатов в качестве основы для всех других функций управления рисками. На основе анализа рисков можно выявить причины отклонений фактических результатов от плановых, а также внутренние резервы управления рисками [3].

Таким образом, возникновение банковских рисков является неотъемлемой частью деятельности кредитных операций и обусловлено их функционированием в сфере денежного обращения. Эффективность системы управления банковскими рисками зависит от способности своевременно реагировать на изменения во внешней и внутренней среде посредством применения инструментов системы управления банковскими рисками. Для того, чтобы повысить эффективность системы управления банковскими рисками необходимо соблюдать ряд принципов, таких как системность, целенаправленность, последовательность, согласованность целей и единство стратегии управления рисками. Система управления рисками будет только тогда выполнять свои задачи, когда на организационном уровне будут реализованы функции планирования, контроля и мониторинга, создания организационной системы с четким распределением функций управления рисками между всеми подразделениями.

\section{Список литературы}

1. Бабаева Н.М. Сущность, понятие и различные подходы к вопросу классификации банковских рисков // Исследование инновационного потенциала общества и формирование направлений его стратегического развития. -2015. - С.35-39.

2. Никонец О. Е., Родный М. П. Кредитный риск коммерческого банка: возможности управления // Научно-методический электронный журнал «Концепт». - 2016. - Т. 15. - С. 2731-2735

3. Пашков, Р.В. Управление рисками и капиталом банка / Р.В. Пашков и др. - М.: Русайнс, 2017. - $96 \mathrm{c}$.

4. Тепман, Л.Н. Управление банковскими рисками: Учебное пособие / Л.Н. Тепман, Н.Д. Эриашвили. - М.: Юнити, 2015. - 311 с.

\section{References}

1. Babaeva N.M. The essence, concept and different approaches to the classification of banking risks // Issledovaniye innovatsionnogo potentsiala obshchestva i formirovaniye napravleniy yego strategicheskogo razvitiya. 2015. - pp.35-39.

2. Nikonets O. E., Rodny M. P. Credit risk of a commercial bank: management capabilities // Nauchnometodicheskiy elektronnyy zhurnal «Kontsept». - 2016. - Vol. 15. - pp. 2731-2735

3. Pashkov, R.V. Upravleniye riskami i kapitalom banka / R.V. Pashkov i dr. - M.: Rusayns, 2017. - 96 p.

Тепман, Л.Н. Управление банковскими рисками: Учебное пособие / Л.Н. Тепман, Н.Д. Эриашвили. - М.: Юнити, 2015. - 311 р. 